\title{
Dibenzoylmethane, hydroxydibenzoylmethane and hydroxymethyldibenzoylmethane inhibit phorbol-12-myristate 13-acetate-induced breast carcinoma cell invasion
}

\author{
YA-FAN LIAO ${ }^{1}$, YEW-MIN TZENG ${ }^{1}$, HUI-CHIH HUNG ${ }^{2}$ and GUANG-YAW LIU ${ }^{3}$ \\ ${ }^{1}$ Department of Applied Chemistry, Chaoyang University of Technology, Taichung 41349; ${ }^{2}$ Department of Life Sciences, \\ National Chung Hsing University, Taichung 40227; ${ }^{3}$ Institute of Microbiology and Immunology, \\ Chung Shan Medical University, Taichung 40201, Taiwan, R.O.C.
}

Received April 18,2014; Accepted December 2, 2014

DOI: $10.3892 / \mathrm{mmr} .2015 .3304$

\begin{abstract}
Dibenzoylmethane (DB), a minor constituent of the root extract of licorice, belongs to the flavonoid family. Hydroxydibenzoylmethane (HDB) and hydroxymethyldibenzoylmethane (HMDB) have an identical structure to $\mathrm{DB}$, but also possess a hydroxyl group and a hydroxyl and methyl group bonded to aromatic rings, respectively. They inhibit cellular proliferation and induce apoptosis in a variety of types of cancer cell, however, the antimetastatic effects of DB, HDB and HMDB on human breast carcinoma cells remain to be elucidated. The present study aimed to clarify the molecular mechanisms underlying the effects of DB and its analogues on phorbol-12-myristate 13-acetate (PMA)-induced MCF-7 cell metastasis. The results revealed that DB, HDB and HMDB inhibited cell migration and invasion. In addition, PMA-mediated MCF-7 cell invasion was inhibited by DB, HDB and HMDB by inhibiting the expression of matrix metalloproteinase (MMP)-9. Rottlerin, a protein kinase C (PKC) $\delta$ inhibitor and LY294002, a phosphatidylinositide 3-kinase (PI3K) inhibitor, reduced the PMA-mediated expression of MMP-9 and cell invasion. Furthermore, DB, HDB and HMDB prevented the activation of PKC $\delta$ and PI3K by inhibiting their phosphorylation. The present study was the first, to the best of our knowledge, to demonstrate the antimetastatic potential of DB, HDB and HDMB, which decreased cancer cell invasion through the PI3K/PKC $\delta$-mediated MMP-9 pathway.
\end{abstract}

Correspondence to: Professor Ya-Fan Liao, Department of Applied Chemistry, Chaoyang University of Technology, 168 Jifeng East Road, Taichung 41349, Taiwan, R.O.C.

E-mail: yafanliao@cyut.edu.tw

Key words: dibenzoylmethane, hydroxydibenzoylmethane, hydroxymethyldibenzoylmethane, invasion, matrix metalloproteinase-9, protein kinase $\mathrm{C} \delta$, phosphatidylinositide 3-kinase

\section{Introduction}

The majority of malignant solid tumors, including breast cancer, proceed to metastases, which is the most frequent cause of cancer-associated mortality (1). Metastasis is the ability of cells to detach from a primary tumor, invade and intravasate into the lymphatic or blood vessels, disseminate in the lymphatic or circulatory systems and initiate the development of new tumor cells in distant organs (2). The migration and invasion of a cancer cell are two crucial steps in metastasis, as is proteolytic enzyme degradation of the extracellular matrix (ECM) (3). Matrix metalloproteinases (MMPs) are essential for ECM degradation and remodeling. MMP-9 and MMP-2 are associated with elevated levels of metastasis in several types of cancer, including breast carcinoma, lung carcinoma and melanoma (4). Inhibition of the expression of MMP-9 by MMP-9 antisense and small interfering RNA constructs suppresses the invasiveness and metastatic ability of tumor cells $(5,6)$. The formation of melanoma and lung carcinoma metastases is reduced in MMP-9-deficient mice (7) and the inhibition of MMP-2 and MMP-9 by potential therapeutic agents, such as snake venom metalloproteinase inhibitor BJ46A, apigenin, quercetin and resveratrol, reduces cancer metastasis in vitro and in vivo (8). Therefore, agents possessing the ability to repress the activation of MMP-2 or MMP-9 warrant development to take advantage of their antimetastatic properties.

The phytochemical, dibenzoylmethane (DB), is a constituent of the root extract of licorice (Glycyrrhiza inflata of the family Leguminosae) and has been identified as a promising antimutagenic and anticarcinogenic compound (9-13). DB inhibits S9-mediated mutagenicity of food-derived heterocyclic amine mutagens (9). Furthermore, it decreases the formation of DNA adducts following exposure to benzo(a) pyrene, 1,6-dinitropyrene and 7,12-dimethylbenz(a)anthracene (DMBA) $(10,11)$. Dietary DB prevents DMBA-induced mammary carcinogenesis and azoxymethane/dextran sulfate sodium-induced colon carcinogenesis $(12,13)$ and deregulation of the cell cycle by DB has been observed in human prostate carcinoma cells (14). Treatment with DB promotes the apoptosis 
of human lung carcinoma cells, epidermoid carcinoma cells and leukemia cells (15-17). Hydroxydibenzoylmethane (HDB) and hydroxymethyldibenzoylmethane (HMDB) are important DB analogues, which are identical in structure to DB with the exception of a hydroxyl group and hydroxyl and methyl groups on one of the aromatic rings, respectively. They are more potent than $\mathrm{DB}$ in inhibiting the proliferation and inducing apoptosis in COLO 205 colorectal carcinoma cells, A431 epidermoid carcinoma cells, A549 lung adenocarcinoma cells and $\mathrm{CH} 27$ lung squamous carcinoma cells $(15,16,18)$. However, whether DB, HDB and HMDB are involved in inhibiting cancer metastasis remains to be elucidated. The present study aimed to examine the effects of DB, HDB and HMDB on the metastatic properties of PMA-treated MCF-7 human breast adenocarcinoma cells.

\section{Materials and methods}

Cell culture and reagents. The MCF-7 human breast adenocarcinoma cell line (Bioresource Collection and Research Center, Hsinchu, Taiwan) was routinely grown in RPMI-1640 medium (Biological Industries, Kibbutz Beit Haemek, Israel), supplemented with $10 \%$ fetal bovine serum (FBS; Biological Industries) at $37^{\circ} \mathrm{C}$ in an atmosphere of $5 \% \mathrm{CO}_{2} / 95 \%$ air under saturating humidity. DB, HDB, HMDB, phorbol-12-myristate 13-acetate (PMA) and 3-(4,5-dimethylthiazol-2-yl)-2,5-diphenyltetrazolium bromide (MTT) were purchased from Sigma-Aldrich (St. Louis, MO, USA). LY294002 was obtained from Merck Millipore (Darmstadt, Germany). Mouse monoclonal MMP-2, mouse monoclonal MMP-9, rabbit polyclonal phosphorylated (phospho)-phosphatidylinositide 3-kinase (PI3K) p85 (Tyr458)/P55 (Tyr199), rabbit polyclonal phospho-protein kinase $\mathrm{C} \delta$ (Thr505) and mouse monoclonal $\beta$-actin antibodies were supplied by Thermo Fisher Scientific, Inc. (Fremont, CA, USA), Santa Cruz Biotechnology, Inc. (Santa Cruz, CA, USA) and Cell Signaling Technology, Inc. (Beverly, CA, USA), respectively.

MTT cell viability assay. The MCF-7 cells $\left(2 \times 10^{4}\right)$ were seeded into 96-well plates for $24 \mathrm{~h}$ prior to treatment with 5, 10, 25, 50 and $100 \mu \mathrm{M}$ DB, HDB or HMDB, followed by the addition of $10 \mathrm{ng} / \mathrm{ml}$ PMA, for $24 \mathrm{~h}$. Following the exposure period, the cells were treated with MTT solution $(5 \mu \mathrm{g} / \mathrm{ml})$ for $4 \mathrm{~h}$. The formazan was solubilized in isopropanol (Merck Millipore) using $0.04 \mathrm{~N} \mathrm{HCl}$ (Sigma-Aldrich) and measured spectrophotometrically at $595 \mathrm{~nm}$ (Synergy ${ }^{\mathrm{TM}}$ HT Multi-Detection Microplate Reader; BioTek Instruments, Inc., Winooski, VT, USA).

Migration assay. Cell migration was assessed by a wound-healing assay using a culture insert (19). Briefly, the cells were seeded into the culture insert (ibidi $\mathrm{GmbH}$, Martinsried, Germany) and grown overnight to $100 \%$ confluence. Following removal of the culture insert, a cell-free gap $(500 \mu \mathrm{m})$ was created and the medium was replaced with 10\% FBS RPMI-1640 medium. The cells were treated with $\mathrm{DB}, \mathrm{HDB}$ or HMDB at 25, 50 and $100 \mu \mathrm{M}$, followed by $10 \mathrm{ng} / \mathrm{ml}$ PMA and images of cell migration from the leading edge were captured and quantified at $12 \mathrm{~h}$, using an Axio Imager A1 microscope and Axio Vision Rel.4.7 software (Carl
Zeiss, Göttingen, Germany). Each value was observed from three randomly selected fields and the data are expressed as the mean number of the migrating cell numbers per field.

Invasion assay. A cellular invasion assay was performed in a modified Boyden chamber (GenePure, Taichung, Taiwan) with $8 \mu \mathrm{m}$ polycarbonate nucleopore filters (Neuro Probe, Inc., Gaithersburg, MD, USA) coated with $250 \mu \mathrm{g} / \mathrm{ml}$ Matrigel (BD Biosciences, San Diego, CA, USA). RPMI-1640 medium containing $2 \%$ FBS was added to the lower compartment of the chamber. The cells $\left(2.5 \times 10^{4}\right)$ were resuspended in RPMI-1640 medium without FBS and added to the upper compartment of the chamber in the presence or absence of $\mathrm{DB}, \mathrm{HDB}$ or HMDB at 25, 50 and $100 \mu \mathrm{M}$, or $1 \mu \mathrm{M}$ rottlerin and $10 \mu \mathrm{M}$ LY294002, followed by $10 \mathrm{ng} / \mathrm{ml}$ PMA for $12 \mathrm{~h}$. Following incubation, the cells were fixed in methanol (Sigma-Aldrich) for $10 \mathrm{~min}$, stained with Giemsa (Merck Millipore) for $30 \mathrm{~min}$ and washed with $\mathrm{H}_{2} \mathrm{O}$ for $3 \mathrm{~min}$. The cells on the upper side of the filters were removed using cotton-tipped swabs and the cells on the underside of the filters were observed and counted under a light microscope (Axio Imager AI).

Gelatin zymography assay. MCF-7 cells were seeded at a concentration of $2 \times 10^{5}$ cells $/ \mathrm{ml}$ and incubated for $24 \mathrm{~h}$ at $37^{\circ} \mathrm{C}$. Following incubation, the culture medium was replaced with serum-free RPMI-1640 medium. The cells were treated with $100 \mu \mathrm{M}$ DB, $50 \mu \mathrm{M}$ HDB or $25 \mu \mathrm{M}$ HMDB, followed by $10 \mathrm{ng} / \mathrm{ml}$ PMA and the supernatants were collected and subjected to gel electrophoresis on an $8 \%$ sodium dodecyl sulfate-polyacrylamide gel electrophoresis (SDS-PAGE) gel containing $0.1 \%$ gelatin. Following electrophoresis, the SDS was removed from the gels by incubation with renaturation buffer (2.7\% Triton X-100; Amresco LLC, Solon, OH, USA) for $1 \mathrm{~h}$. The gels were gently agitated and incubated at $37^{\circ} \mathrm{C}$ for $24 \mathrm{~h}$ in the developing buffer containing $50 \mathrm{mM}$ Tris- $\mathrm{HCl}$ (pH 7.5), 0.2 $\mathrm{M} \mathrm{NaCl}, 0.2 \%$ Brij-35 and $5 \mathrm{mM} \mathrm{CaCl}_{2}$ and stained using coomassie brilliant blue (USB Corporation, Cleveland, $\mathrm{OH}, \mathrm{USA}$ ) and destained with destaining solution (7\% acetic acid, 5\% methanol, Sigma-Aldrich; 88\% $\mathrm{H}_{2} \mathrm{O}$ ) for $30 \mathrm{~min}$, respectively. The proteolytic activity of MMP-9 and MMP-2 were observed as clear bands against the blue background of the stained gelatin.

Reverse transcription polymerase chain reaction (RT-PCR). The RNA was isolated from the cells using TRIzol reagent (MDBio, Inc., Piscataway, NJ, USA) according to the manufacturer's instructions. The synthesis of complementary DNA (cDNA) was performed using the extracted total RNA (3 $\mu \mathrm{g})$, reverse transcriptase (200 units; Promega Corporation, Madison, WI, USA) and dT15 primers $(0.5 \mu \mathrm{g}$; MDBio, Inc.) and the reaction mixture was incubated for $90 \mathrm{~min}$ at $37^{\circ} \mathrm{C}$. For the PCR assay, $0.04 \mu \mathrm{g}$ cDNA was added to mixture buffer containing $75 \mathrm{mM}$ Tris- $\mathrm{HCl}(\mathrm{pH} 8.8)$, $20 \mathrm{mM}\left(\mathrm{NH}_{4}\right)_{2} \mathrm{SO}_{4}, 0.01 \%$ Tween-20 (v/v), $1 \mathrm{mM} \mathrm{MgCl}$, $0.2 \mathrm{mM}$ dNTPs, $0.5 \mu \mathrm{M}$ forward and reverse primers and 1 unit Taq DNA polymerase (MDBio, Piscataway, NJ, USA). The PCR was performed as follows: $5 \mathrm{~min}$ at $95^{\circ} \mathrm{C}, 36$ cycles (30 sec at $5^{\circ} \mathrm{C} ; 30 \mathrm{sec}$ at $55^{\circ} \mathrm{C}$ and $90 \mathrm{sec}$ at $72^{\circ} \mathrm{C}$ ) and $10 \mathrm{~min}$ at $72^{\circ} \mathrm{C}$ using a $\mathrm{PC} 818$ program temperature control system 

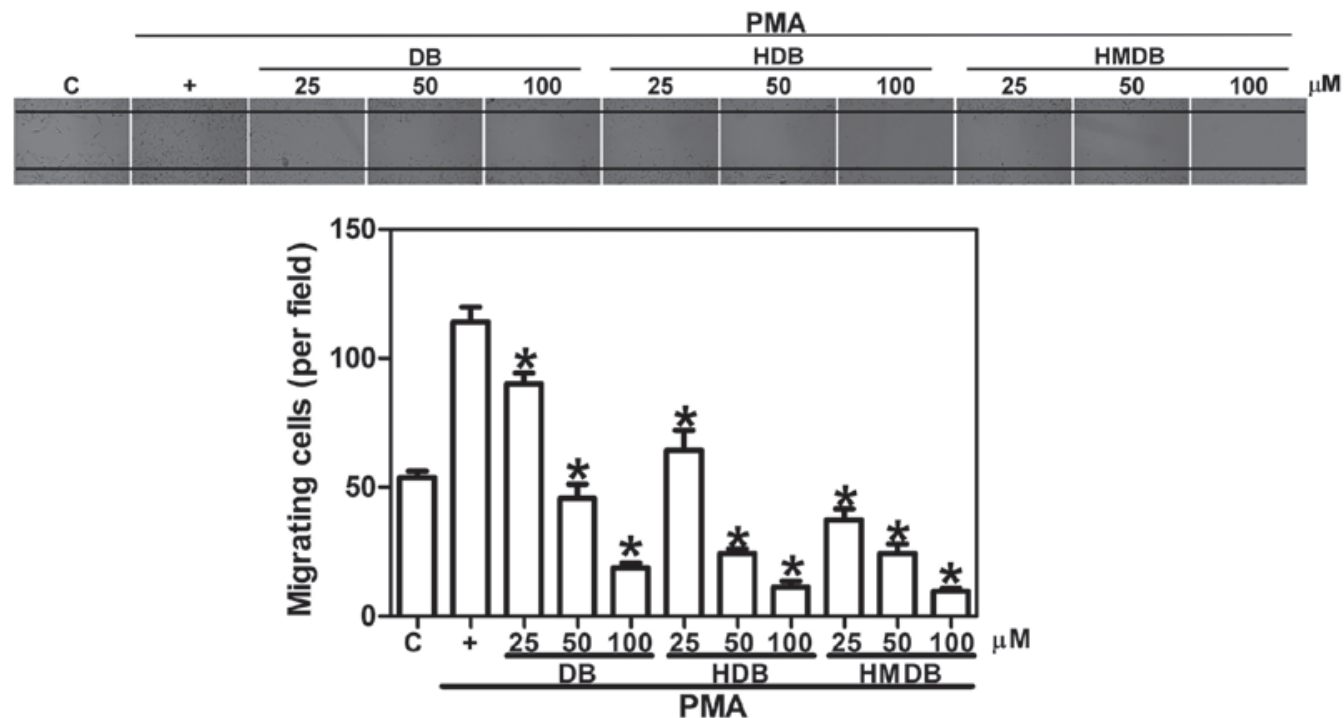

Figure 1. Effects of DB and its analogues, HDB and HMDB, on MCF-7 breast cancer cell migration. The MCF-7 cells were treated with various concentrations of DB, HDB and HMDB, followed by $10 \mathrm{ng} / \mathrm{ml}$ PMA for $12 \mathrm{~h}$. Images of the migrating cells were captured using phase contrast microscopy (magnification, $\mathrm{x} 100$ ). The quantification data are expressed as the mean \pm standard deviation of three independent experiments. ${ }^{*} \mathrm{P}<0.05$, compared with the PMA only group. DB, dibenzoylmethane; HDB, hydroxydibenzoylmethane; HMDB, hydroxymethyldibenzoylmethane; PMA, phorbol-12-myristate 13-acetate; C, control.

(Astec, Fukuoka, Japan). The PCR products were analyzed on a $2 \%$ agarose gel. The following primer pairs were used: $\beta$-actin (309 bp) forward 5'-AGCGGGAAATCGTGCGTG-3' and reverse 5'-CAGGGTACATGGTGGTGC-3'; MMP-2 (346 bp) forward 5'-CTTTGACGGTAAGGACGG-3' and reverse 5'-CTGGAAGCGGAATGGAA-3' and MMP-9 (479 bp) forward 5'-CAACATCACCTATTGGATCC-3' and reverse 5'-CGGGTGTAGAGTCTCTCGCT-3'.

Immunoblotting. To purify the total protein, the cells were harvested and lysed in cold lysis buffer containing $10 \%$ (v/v) glycerol, 1\% (v/v) Triton X-100, $1 \mathrm{mM}$ sodium orthovanadate, $1 \mathrm{mM}$ EGTA, $10 \mathrm{mM} \mathrm{NaF}, 1 \mathrm{mM}$ sodium pyrophosphate, $20 \mathrm{mM}$ Tris (pH 7.9), $100 \mu \mathrm{M} \beta$-glycerophosphate, $137 \mathrm{mM} \mathrm{NaCl}, 5 \mathrm{mM}$ EDTA, $1 \mathrm{mM}$ PMSF, $10 \mu \mathrm{g} / \mathrm{ml}$ aprotinin and $10 \mu \mathrm{g} / \mathrm{ml}$ leupeptin. Equal concentrations of protein were separated on SDS-PAGE gels and then transferred onto polyvinylidene difluoride (PVDF) membranes (Pall Corporation, Ann Arbor, MI, USA). Following blotting, the PVDF membranes were incubated with anti-phospho-PKC $\delta$ (Thr505), anti-phospho-PI3K p85 (Tyr458)/anti-phospho-p55 (Tyr199) or anti- $\beta$-actin antibodies (dilutions 1:2,500) for $6 \mathrm{~h}$ at $4^{\circ} \mathrm{C}$. Following washing with washing solution $[50 \mathrm{mM}$ tris- $\mathrm{HCl}(\mathrm{pH} 7.5), 150 \mathrm{mM} \mathrm{NaCl}, 0.1 \%$ Tween-20 (v/v)], the secondary antibody labeled with horseradish-peroxidase was added for $1 \mathrm{~h}$ at $4^{\circ} \mathrm{C}$. The targeted proteins were visualized using enhanced chemiluminescence (Western Lightning Plus ECL; PerkinElmer, Inc., Waltham, MA, USA).

Statistical Analysis. Data are expressed as the mean \pm standard deviation. GraphPad Prism 5 software (GraphPad Software, Inc., La Jolla, CA, USA) was used for statistical analysis. Statistical comparisons were made by a one-way analysis of variance, followed by Dunnett's multiple-comparison test. $\mathrm{P}<0.05$ was considered to indicate a statistically significant difference.

\section{Results}

$D B, H D B$ and $H M D B$ reduce PMA-induced $M C F-7$ cancer cell migration and invasion. To determine whether DB and its analogues were involved in inhibiting the PMA-induced migration of the MCF-7 cells, the cells were treated with PMA and/or DB, HDB or HMDB and migration was assessed using a wound-healing assay. Treatments with DB, HDB and HMDB significantly inhibited PMA-induced cell migration (Fig. 1). Treatment with 25, 50 and $100 \mu \mathrm{M}$ DB reduced the migration of the cancer cells by 21,60 and $84 \%$, respectively, compared with those treated with PMA only. PMA-induced MCF-7 cell migration was reduced by 44,79 and $90 \%$ following exposure to 25,50 and $100 \mu \mathrm{M}$ HDB, respectively, which was more markedly inhibited to 67,79 and $92 \%$ following treatment with 25, 50 and $100 \mu \mathrm{M}$ HMDB, respectively, compared with those treated with PMA only. To undergo invasion, cancer cells promote the degradation of the extracellular matrix in order to cross it (3). Therefore, the effect of DB, HDB or HMDB on PMA-induced MCF-7 cancer cell invasion was determined using an invasion chamber assay. The MCF-7 cells were seeded onto Matrigel-coated filters in the presence of $\mathrm{DB}$, HDB or HMDB at 25, 50 and $100 \mu \mathrm{M}$ and the number of cells, which invaded through the Matrigel were counted following incubation for $12 \mathrm{~h}$. Treatments with DB, HDB and HMDB significantly inhibited PMA-induced cell invasion (Fig. 2). Treatment with 25, 50 and $100 \mu \mathrm{M}$ DB reduced the cancer cell invasion by 1,32 and $68 \%$, respectively, compared with the PMA-only-treated cells. The PMA-induced MCF-7 cell invasion was reduced by 33,81 and $90 \%$ following exposure to 25,50 and $100 \mu \mathrm{M}$ HDB, respectively, and was significantly inhibited to 57,75 and 98\% following treatment with 25,50 and $100 \mu \mathrm{M}$ of HMDB, respectively, compared with the PMA-only group. On the basis of these results, it was concluded that DB, HDB and HMDB inhibited the migration and invasion of the MCF-7 cells. 


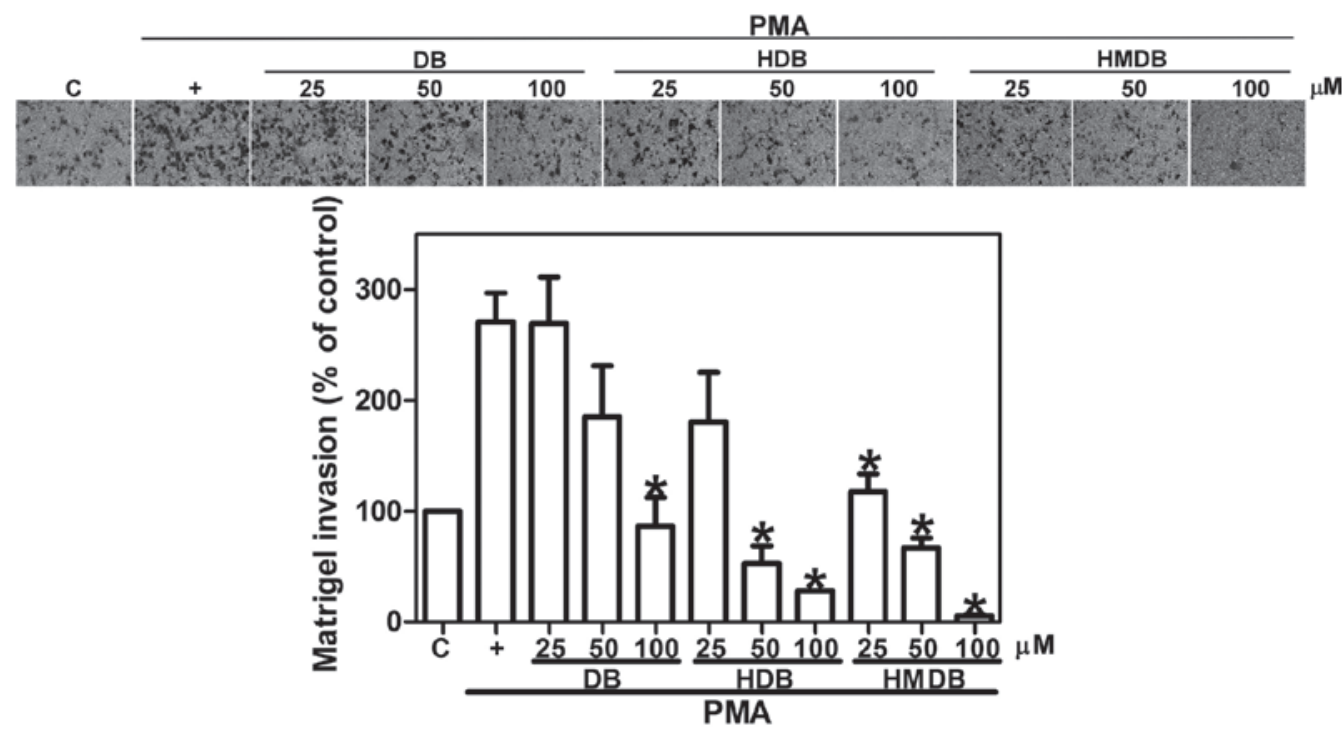

Figure 2. Effects of DB, HDB and HMDB on MCF-7 breast cancer cell invasion. The MCF-7 cells were treated with various concentrations of DB, HDB and HMDB, followed by $10 \mathrm{ng} / \mathrm{ml}$ PMA for $12 \mathrm{~h}$. The invasive ability was assessed using a Matrigel-coated in vitro invasion assay, as described (magnification, $\mathrm{x} 200$ ). The quantification data are expressed as the mean \pm standard deviation of three independent experiments. ${ }^{*} \mathrm{P}<0.05$, compared with the PMA only group. DB, dibenzoylmethane; HDB, hydroxydibenzoylmethane; HMDB, hydroxymethyldibenzoylmethane; PMA, phorbol-12-myristate 13-acetate; C, control.
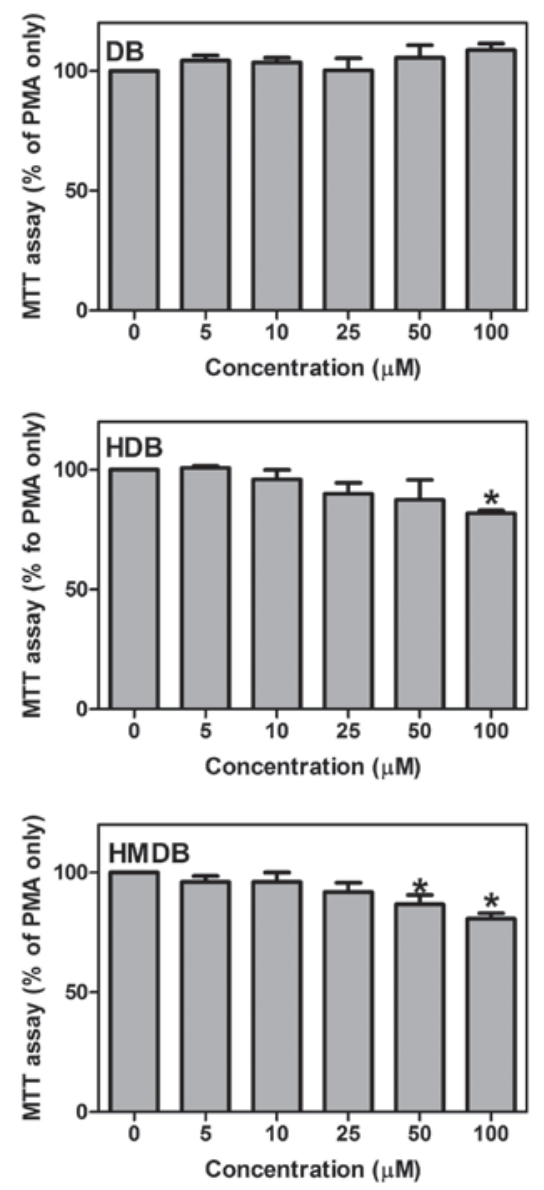

Figure 3. Effects of DB, HDB and HMDB on MCF-7 breast cancer cell viability following PMA treatment. The MCF-7 cells were treated with various concentrations of $\mathrm{DB}, \mathrm{HDB}$ and $\mathrm{HMDB}$, followed by the addition of $10 \mathrm{ng} / \mathrm{ml}$ PMA for $24 \mathrm{~h}$. The cell viability was assessed using an MTT assay. The quantification data are expressed as the mean \pm standard deviation of three independent experiments. ${ }^{*} \mathrm{P}<0.05$, compared with the PMA only group. DB, dibenzoylmethane; HDB, hydroxydibenzoylmethane; HMDB, hydroxymethyldibenzoylmethane; PMA, phorbol-12-myristate 13-acetate; MTT, 3-(4,5-dimethylthiazol-2-yl)-2,5-diphenyltetrazolium bromide.
Effects of $D B, H D B$ and $H M D B$ on the viability of the PMA-treated MCF-7 cells. To determine the cytotoxicity of DB and its analogues, HDB and HMDB, on the PMA-mediated MCF-7 cancer cells, the cells were treated with different concentrations $(5,10,25,50$ and $100 \mu \mathrm{M})$ of $\mathrm{DB}$, HDB or HMDB followed by the addition of PMA for $24 \mathrm{~h}$. The cellular viability was then assessed using an MTT assay. The proportional viability (\%) of the cells was determined by comparing each treated group with the PMA-only group, the viability of which was assumed to be $100 \%$ (Fig. 3). Treatment of the MCF-7 cells with DB, up to a maximal concentration of $100 \mu \mathrm{M}$, caused no significant change in cell viability. The cells had significantly lower viability following treatment with $100 \mu \mathrm{M}$ HDB and $50 \mu \mathrm{M}$ HMDB. Therefore, the antimetastatic effects of DB, HDB and HMDB were not associated with cell viability.

$D B$ and its analogues inhibit the PMA-induced expression of MMP-9. The MMPs are a family of extracellular matrix degrading enzymes, which are associated with cancer cell metastasis. The type IV collagenases and gelatinases, MMP-9 and MMP-2, have been linked with high metastatic potential in breast carcinoma (20). Therefore, the effects of DB, HDB and HMDB on the enzyme activities and the gene expression levels of MMP-2 and MMP-9 were examined. The MCF-7 cells were treated with various concentrations of $\mathrm{DB}, \mathrm{HDB}$ or HMDB followed by treatment with PMA in serum-free medium. The enzyme activities of the secreted MMP-2 and MMP-9 were assayed by gelatin zymography. As shown in Fig. 4A, DB, HDB and HMDB inhibited the enzyme activity of MMP-9, but not MMP-2, in a time-dependent manner. To determine whether DB, HDB and HMDB can inhibit the enzymatic activity of the secreted MMP-9 through the direct inhibition of these enzymes, various concentrations of DB, HDB and HMDB were incubated with conditioned medium derived from PMA-treated MCF-7 cells. The enzymatic activities of MMP-9 and MMP-2 
A

PMA

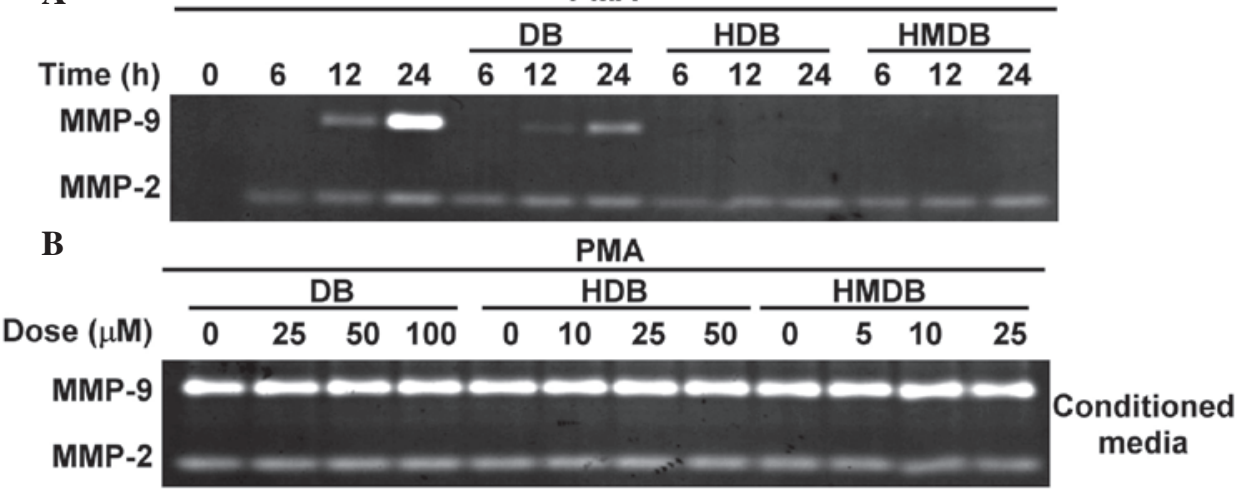

C



D


Figure 4. DB, HDB and HMDB inhibit the PMA-induced expression of MMP-9 in MCF-7 cells. (A) MCF-7 cells were treated with $100 \mu \mathrm{M}$ DB, $50 \mu \mathrm{M}$ HDB and $25 \mu \mathrm{M}$ HMDB, followed by the addition of $10 \mathrm{ng} / \mathrm{ml}$ PMA for 6,12 and $24 \mathrm{~h}$. The activity of the secreted MMP-9 and MMP-2 proteins was analyzed by gelatin zymography. (B) MMP-9 and MMP-2, derived from PMA-treated conditioned medium following stimulation for $24 \mathrm{~h}$, was incubated with various concentrations of DB, HDB and HMDB for $30 \mathrm{~min}$. The enzyme activities of MMP-2 and MMP-9 were analyzed using gelatin zymography. The light areas represent zones of lysis in gelatin gel were quantified by laser scanning densitometry. (C) MCF-7 cells were treated with DB, HDB and HMDB followed by the addition of $10 \mathrm{ng} / \mathrm{ml}$ PMA for $24 \mathrm{~h}$. The protein and mRNA expression levels of MMP-9 and MMP-2 were analyzed using immunoblotting and reverse transcription polymerase chain reaction. (D) MCF-7 cells were treated with or without M9I-I and with PMA and then invasive ability was assessed using a Matrigel invasion assay (magnification, $\mathrm{x} 200$ ). The data are expressed as the mean \pm standard deviation " $\mathrm{P}<0.05$, compared with the PMA only group. DB, dibenzoylmethane; HDB, hydroxydibenzoylmethane; HMDB, hydroxymethyldibenzoylmethane; PMA, phorbol-12-myristate 13-acetate; M9I-I, MMP-9 inhibitor I; C, control.

were assessed using gelatin zymography. As shown in Fig. 4B, MMP-9 and MMP-2 activity was detected in the conditioned media, and no significant differences were observed between the groups with or without treatment. Subsequently, to determine whether the inhibition of the enzymatic activities of MMP-9 and MMP-2 by DB, HDB or HMDB was due to a decreased level of mRNA transcription and protein synthesis, immunoblotting and RT-PCR were performed to examine the protein and mRNA expression levels of MMP-9 and MMP-2. As shown in Fig. 4C, DB, HDB and HMDB reduced the protein expression of the PMA-induced MMP-9, however no changes in the protein or mRNA expression of MMP-2 were observed. MMP-9 inhibitor I, a cell-permeable and reversible inhibitor of MMP-9, deceased the PMA-induced MCF-7 cell invasion (Fig. 4D). These results demonstrated that DB, HDB and HMDB disrupted the mRNA transcription and protein synthesis of MMP-9 in PMA-mediated metastasis.
$P M A$-induced activation of $P K C \delta$ and $P I 3 K$ is reduced by $D B, H D B$ and $H M D B$. The PKC 8 and PI3K signaling pathways are important in cancer invasion $(21,22)$. The present study aimed to determine the involvement of the activation of PKC $\delta$ and PI3K in the PMA-induced expression of MMP-9. The MCF-7 cells were treated with rottlerin (Rot), a PKC $\delta$ inhibitor or LY294002, a PI3K inhibitor, for $24 \mathrm{~h}$, followed by the addition of PMA. As shown in Fig. 5A, Rot and LY effectively reduced the PMA-induced enzymatic activity and the mRNA expression of MMP-9 in a dose-dependent manner, as measured by gelatin zymography and RT-PCR, respectively. In addition, it was observed that the MCF-7 cells treated with $1 \mu \mathrm{M}$ Rot and $10 \mu \mathrm{M}$ LY reduced PMA-induced MCF-7 cell invasion (Fig. 5B). The activity of PKC $\delta$ was increased by the phosphorylation of Thr 505 and the activity of PI3K kinase was increased by the phosphorylation of Tyr458 in PI3K-p85 and of Tyr199 in PI3K-p55. Therefore, the 
A



B

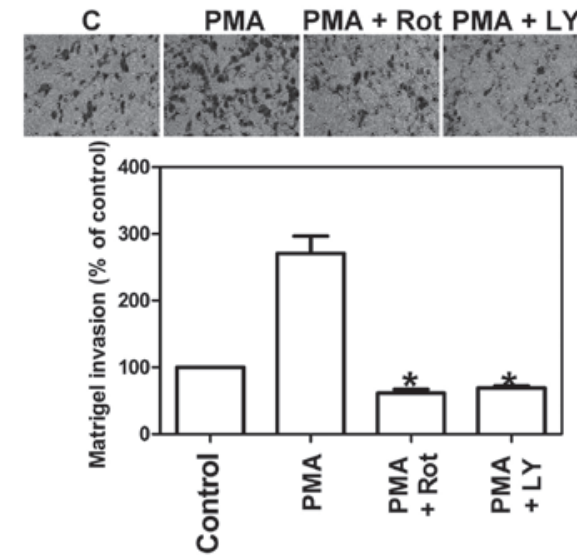

C

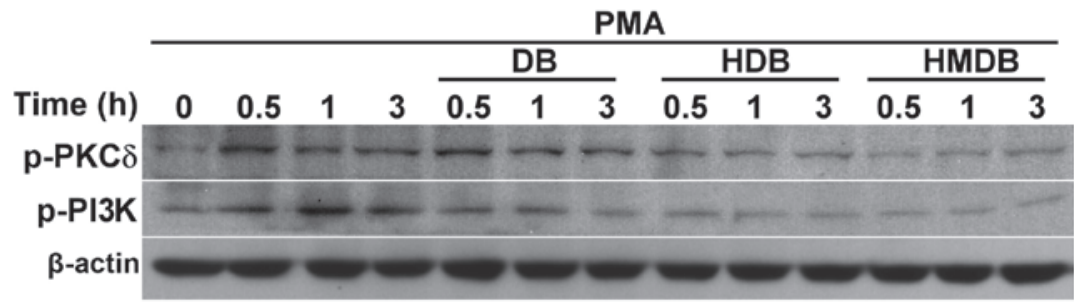

Figure 5. Effects of DB, HDB and HMDB on the PMA-induced activation of PKCD and PI3K. (A) MCF-7 cells were treated with various concentrations of Rot or LY and the addition of PMA for $24 \mathrm{~h}$. The activity and mRNA expression of MMP-9 were assessed using gelatin zymography and reverse transcription polymerase chain reaction, respectively. (B) MCF-7 cells were treated with Rot or LY followed by PMA and the invasive ability was assessed using a Matrigel invasion assay (magnification, $\mathrm{x} 200$ ). The data are expressed as the mean \pm standard deviation. ${ }^{*} \mathrm{P}<0.05$ compared with the PMA only group. (C) MCF-7 cells were treated with $100 \mu \mathrm{M} \mathrm{DB}, 50 \mu \mathrm{M}$ HDB and $25 \mu \mathrm{M}$ HMDB followed by the addition of PMA for $0.5,1$ and $3 \mathrm{~h}$. The expression levels of p-PKC $\delta$ and p-PI3K were analyzed by immunoblotting. DB, dibenzoylmethane; HDB, hydroxydibenzoylmethane; HMDB, hydroxymethyldibenzoylmethane; PMA, phorbol-12-myristate 13-acetate; PKCס, protein kinase C $\delta$; PI3K, phosphatidylinositide 3-kinase; Rot, rottlerin; LY, LY294002; p-, phosphorylated; MMP, metalloproteinase, Zym, zymography; C, control.

phosphorylation levels of PKC 8 -Thr505, PI3K p85-Tyr458 and p55-Tyr199 were assessed by immunoblotting. As shown in Fig. 5C, the PMA-stimulated MCF-7 cells exhibited increased phosphorylation levels of PKC $\delta$ and PI3K. The increases in phosphorylated PKC $\delta$ and PI3K by PMA-stimulation were suppressed by treatment for $0.5,1$ and $3 \mathrm{~h}$ with $100 \mu \mathrm{M} \mathrm{DB}$, $50 \mu \mathrm{M}$ HDB and $25 \mu \mathrm{M}$ HMDB. The order of potency of these compounds on the inhibition of PKC $\delta$ and PI3K phosphorylation were in the order $\mathrm{HMDB}>\mathrm{HDB}>\mathrm{DB}$.

\section{Discussion}

The cause of mortality in the majority of patients with breast cancer is not from the primary cancer growth, but due to spread of the cancer cells to other parts of the body (23). Synthesized chemotherapeutic compounds demonstrate efficacy in treating metastatic breast cancer, however, certain chemotherapeutic agents possess toxic side effects (24). Therefore, the identification of naturally-derived antimetastatic, non-toxic, compounds is of particular interest. Natural products containing phenolic compounds have been widely reported to have the ability to prevent cancer metastasis (25). Flavonoids are a large subclass of phenolic compounds, prevalent in food and herbal nutraceuticals (26). DB, a $\beta$-diketone analogue of curcumin, belongs to the flavonoid family. Skin cancer frequently occurs at sun-exposed sites of the body, and sunscreen derivatives from DB have been used for protection against ultraviolet radiation (27). DB modulates the phase I/phase II detoxification 
enzymatic systems $(10,28)$ and with its analogues, HDB and HMDB, induces apoptosis in various types of cancer (15-18). However, their antimetastatic effects remain to be elucidated. The present study found that DB, HDB and HMDB significantly inhibited PMA-mediated MCF-7 cell migration and invasion (Figs. 1 and 2) and was the first, to the best of our knowledge, to demonstrate that DB, HDB and HMDB inhibiti cancer cell migration and invasion.

MMPs are a family of $\mathrm{Zn}^{2+}$ - and $\mathrm{Ca}^{2+}$-dependent endopeptidases, comprising four subclasses (collagenases, gelatinases, stromelysins and membrane-type MMPs) based on their substrate (4). Increased levels of MMP-9 and MMP-2 are functionally associated with metastasis in several types of malignant tumor, including breast cancer $(4,20)$. The present study indicated that DB, HDB and HMDB inhibited the expression of MMP-9, but not MMP-2, following PMA treatment (Fig 4). MMP-2 is generally constitutively expressed in tissues and is maximally present in malignant neoplasms (29). By contrast, the expression of MMP-9 can be induced by various growth factors and inflammatory mediators during pathological states and by agents, including PMA $(19,30)$. PMA is a tumor promoter and an inflammatory stimulator, which increases the invasiveness of cancer cells, including breast cancer, by activating MMP-9 (19). DB is an effective inhibitor of PMA-induced mouse skin inflammation and tumor promotion (31). In the present study, the potency of inhibition by DB and its structural analogs on the expression of MMP-9 and their effects on the invasive potential of the PMA-treated MCF-7 cells was in the order HMDB $>$ HDB $>$ DB. Higher numbers of $\mathrm{OH}$ groups are present in flavonoid structures with increased anti-MMP activation $(32,33)$. Compared with DB and HDB, HMDB has more marked anticancer effects in solid cancer cell lines (15).

PMA is a diacylglycerol mimic, which directly binds to and activates classical $(\alpha, \beta$ and $\gamma$ ) and novel $(\delta, \varepsilon, \theta$ and $\eta)$ PKC isozymes (34). The activation of PKC involves the phosphorylation of $\mathrm{PKC}$ isoforms, causing cell proliferation, apoptosis, and cancer metastasis. The phosphorylation of PKC $\delta$ is involved in promoting cell invasion (35). PKC $\delta$ is an important signaling molecule for the expression of MMP-9 in cancer cell lines, including MCF-7 human breast carcinoma cells, CaSki cells and HP-75 pituitary adenoma cells $(32,36,37)$. The present study found that the $\mathrm{DB}$ analogues inhibited the phosphorylation of PKC $\delta$ in the MCF-7 cells following PMA treatment (Fig. 5C). PKC activates Ha-Ras-mediated signal transduction pathways (38) and human telomerase reverse transcriptase (hTERT) is phosphorylated by PKC $\delta$ (39). DB attenuates the expression of oncogenes Ha-Ras and hTERT oncogenes (40). The activation of MMP-9 is downstream of Ha-Ras (41) and knockdown of hTERT reduces the expression of MMP-9 in human glioblastoma cell lines (42). Inhibiting the activity of PKC $\delta$ by Rot enhances p38 mitogen activated protein kinase (MAPK) activation (43). HMDB activates p38 MAPK signaling (44), which suppresses the expression of MMP-9 in human stomach cancer (45). Nutraceuticals derived from spices, including curcumin, capsaicin and diosgenin, target the PI3K signaling pathway to regulate cancer metastasis (25) and activation of this pathway in breast cancer is associated with a poor prognosis (46). In the present study, DB, HDB and HMDB prevented the PMA-induced phosphorylation of PI3K in the MCF-7 cells (Fig. 5C). PI3Ks are heterodimeric serine/threonine kinases consisting of p110 catalytic and regulatory subunits and tyrosine phosphorylation of the $\mathrm{p} 85$ regulatory subunit reduces its inhibitory activity on PI3K (47). The PI3K inhibitor, LY294002, significantly diminishes the expression of phosphorylated PI3K-p85 (Tyr458)/p55 (Tyr199) (48). The results of the present and previous studies have revealed that the inhibition of PI3K activity can suppress the expression of MMP-9 and cancer cell invasion (21). These findings suggest that DB analogues inhibits PMA-induced metastasis by interfering with the $\mathrm{PI} 3 \mathrm{~K} / \mathrm{PKC} \delta$-mediated expression of MMP-9.

In conclusion, the present study demonstrated that DB, HDB and HMDB exerted antimetastatic effects in PMA-treated MCF-7 breast cancer cells. The mechanism underlying this was the inhibiton of the activity and expression of MMP-9 via the PKCS and PI3K signaling pathways. Therefore, DB, HDB and HDMB may be potent chemopreventive agents in therapeutic strategies for metastatic cancers in the future.

\section{Acknowledgements}

This study was supported by grants from the National Science Council of Taiwan (NSC 98-2320-B-324-001 and NSC 102-2320-B-324-002)

\section{References}

1. Weigelt B, Peterse JL and van 't Veer LJ: Breast cancer metastasis: markers and models. Nat Rev Cancer 5: 591-602, 2005.

2. Scully OJ, Bay BH, Yip G and Yu Y: Breast cancer metastasis. Cancer Genomics Proteomics 9: 311-320, 2012.

3. Stetler-Stevenson WG, Aznavoorian S and Liotta LA: Tumor cell interactions with the extracellular matrix during invasion and metastasis. Annu Rev Cell Biol 9: 541-573, 1993.

4. Vihinen P and Kahari VM: Matrix metalloproteinases in cancer: prognostic markers and therapeutic targets. Int J Cancer 99: 157-166, 2002.

5. Kondraganti S, Mohanam S, Chintala SK, et al: Selective suppression of matrix metalloproteinase-9 in human glioblastoma cells by antisense gene transfer impairs glioblastoma cell invasion. Cancer Res 60: 6851-6855, 2000.

6. Lakka SS, Gondi CS, Yanamandra N, et al: Inhibition of cathepsin B and MMP-9 gene expression in glioblastoma cell line via RNA interference reduces tumor cell invasion, tumor growth and angiogenesis. Oncogene 23: 4681-4689, 2004.

7. Itoh T, Tanioka M, Matsuda $\mathrm{H}$, et al: Experimental metastasis is suppressed in MMP-9-deficient mice. Clin Exp Metastasis 17: 177-181, 1999.

8. Ji MK, Shi Y, Xu JW, et al: Recombinant snake venom metalloproteinase inhibitor BJ46A inhibits invasion and metastasis of B16F10 and $\mathrm{MHCC} 97 \mathrm{H}$ cells through reductions of matrix metalloproteinases 2 and 9 activities. Anticancer Drugs 24: 461-472, 2013.

9. Shishu, Singla AK and Kaur IP: Inhibitory effect of dibenzoylmethane on mutagenicity of food-derived heterocyclic amine mutagens. Phytomedicine 10: 575-582, 2003.

10. Lin CC, Lu YP, Lou YR, et al: Inhibition by dietary dibenzoylmethane of mammary gland proliferation, formation of DMBA-DNA adducts in mammary glands, and mammary tumorigenesis in Sencar mice. Cancer Lett 168: 125-132, 2001.

11. Singletary K and MacDonald C: Inhibition of benzo[a]pyrene- and 1,6-dinitropyrene-DNA adduct formation in human mammary epithelial cells bydibenzoylmethane and sulforaphane. Cancer Lett 155: 47-54, 2000 .

12. Cheung KL, Khor TO, Huang MT and Kong AN: Differential in vivo mechanism of chemoprevention of tumor formation in azoxymethane/dextran sodium sulfate mice by PEITC and DBM. Carcinogenesis 31: 880-885, 2010. 
13. Singletary K, MacDonald C, Iovinelli M, Fisher C and Wallig M: Effect of the beta-diketones diferuloylmethane (curcumin) and dibenzoylmethane on rat mammary DNA adducts and tumors induced by 7,12-dimethylbenz[a]anthracene. Carcinogenesis 19 : $1039-1043,1998$.

14. Jackson KM, DeLeon M, Verret CR and Harris WB: Dibenzoylmethane induces cell cycle deregulation in human prostate cancer cells. Cancer Lett 178: 161-165, 2002.

15. Pan MH, Sin YH,Lai CS, et al: Induction of apoptosis by 1-(2-hydr oxy-5-methylphenyl)-3-phenyl-1,3-propanedione through reactive oxygen species production, GADD153 expression, and caspases activation in human epidermoid carcinoma cells. J Agric Food Chem 53: 9039-9049, 2005.

16. Weng CJ, Yang YT, Ho CT and Yen GC: Mechanisms of apoptotic effects induced by resveratrol, dibenzoylmethane, and their analogues on human lung carcinoma cells. J Agric Food Chem 57: 5235-5243, 2009.

17. Wu CL, Liao YF, Hung YC, Lu KH, Hung HC and Liu GY: Ornithine decarboxylase prevents dibenzoylmethane-induced apoptosis through repressing reactive oxygen species generation. J Biochem Mol Toxicol 25: 312-319, 2011.

18. Pan MH, Huang MC, Wang YJ, Lin JK and Lin CH: Induction of apoptosis by hydroxydibenzoylmethane through coordinative modulation of cyclin D3, Bcl-X(L), and Bax, release of cytochrome $\mathrm{c}$, and sequential activation of caspases in human colorectal carcinoma cells. J Agric Food Chem 51: 3977-3984, 2003.

19. Liao YF, Rao YK and Tzeng YM: Aqueous extract of Anisomeles indica and its purified compound exerts anti-metastatic activity through inhibition of NF-kappaB/AP-1-dependent MMP-9 activation in human breast cancer MCF-7 cells. Food Chem Toxicol 50: 2930-2936, 2012

20. Duffy MJ, Maguire TM, Hill A, McDermott E and O'Higgins N: Metalloproteinases: Role in breast carcinogenesis, invasion and metastasis. Breast Cancer Res 2: 252-257, 2000.

21. Park SK, Hwang YS, Park KK, Park HJ, Seo JY and Chung WY: Kalopanaxsaponin A inhibits PMA-induced invasion by reducing matrix metalloproteinase-9 via PI3K/Akt- and PKCdelta-mediated signaling in MCF-7 human breast cancer cells. Carcinogenesis 30: 1225-1233, 2009.

22. YuHS,Lin THandTang CH: Bradykininenhancescell migrationin human prostate cancer cells through $\mathrm{B} 2$ receptor/PKCdelta/c-Src dependent signaling pathway. Prostate 73: 89-100, 2013.

23. Pockaj BA, Wasif N, Dueck AC, et al: Metastasectomy and surgical resection of the primary tumor in patients with stage IV breast cancer: time for a second look? Ann Surg Oncol 17: 2419-2426, 2010

24. Johnson KA and Brown PH: Drug development for cancer chemoprevention: focus on molecular targets. Semin Oncol 37: 345-358, 2010

25. Weng CJ and Yen GC: Chemopreventive effects of dietary phytochemicals against cancer invasion and metastasis: phenolic acids, monophenol, polyphenol, and their derivatives. Cancer Treat Rev 38: 76-87, 2012.

26. Kandaswami C, Lee LT, Lee PP, et al: The antitumor activities of flavonoids. In Vivo 19: 895-909, 2005.

27. Nogueira MA, Magalhaes EG, Magalhaes AF, et al: A novel sunscreen agent having antimelanoma activity. Farmaco 58: $1163-1169,2003$

28. Dinkova-Kostova AT and Talalay P: Relation of structure of curcumin analogs to their potencies as inducers of Phase 2 detoxification enzymes. Carcinogenesis 20: 911-914, 1999.

29. Brummer O, Athar S, Riethdorf L, Loning T and Herbst $\mathrm{H}$ Matrix-metalloproteinases 1,2, and 3 and their tissue inhibitors 1 and 2 in benign and malignant breast lesions: an in situ hybridization study. Virchows Arch 435: 566-573, 1999.

30. Mishra A, Paul S and Swarnakar S: Downregulation of matrix metalloproteinase- 9 by melatonin during prevention of alcohol-induced liver injury in mice. Biochimie 93: 854-866, 2011.
31. Huang MT, Lou YR, Xie JG, et al: Effect of dietary curcumin and dibenzoylmethane on formation of 7,12-dimethylbenz[a] anthracene-induced mammary tumors and lymphomas/leukemias in Sencar mice. Carcinogenesis 19: 1697-1700, 1998.

32. Lin CW, Hou WC, Shen SC, et al: Quercetin inhibition of tumor invasion via suppressing PKC delta/ERK/AP-1-dependent matrix metalloproteinase-9 activation in breast carcinoma cells. Carcinogenesis 29: 1807-1815, 2008.

33. Sim GS, Lee BC, Cho HS, et al: Structure activity relationship of antioxidative property of flavonoids and inhibitory effect on matrix metalloproteinase activity in UVA-irradiated human dermal fibroblast. Arch Pharm Res 30: 290-298, 2007.

34. Liu WS and Heckman CA: The sevenfold way of PKC regulation. Cell Signal 10: 529-542, 1998.

35. Matsuoka H, Tsubaki M, Yamazoe Y, et al: Tamoxifen inhibits tumor cell invasion and metastasis in mouse melanoma through suppression of PKC/MEK/ERK and PKC/PI3K/Akt pathways. Exp Cell Res 315: 2022-2032, 2009.

36. Hussaini IM, Trotter C, Zhao Y, et al: Matrix metalloproteinase-9 is differentially expressed in nonfunctioning invasive and noninvasive pituitary adenomas and increases invasion in human pituitary adenoma cell line. Am J Pathol 170: 356-365, 2007.

37. Woo JH, Lim JH, Kim YH, et al: Resveratrol inhibits phorbol myristate acetate-induced matrix metalloproteinase-9 expression by inhibiting JNK and PKC delta signal transduction. Oncogene 23: 1845-1853, 2004.

38. Vuong H, Patterson T, Shapiro P, et al: Phorbol ester-induced expression of airway squamous cell differentiation marker, SPRR1B, is regulated by protein kinase Cdelta/Ras/MEKK1/MKK1-dependent/AP-1 signal transduction pathway. J Biol Chem 275: 32250-32259, 2000.

39. Chang JT, Lu YC, Chen YJ, et al: hTERT phosphorylation by $\mathrm{PKC}$ is essential for telomerase holoprotein integrity and enzyme activity in head neck cancer cells. Br J Cancer 94: 870-878, 2006

40. Lin CC, Tsai YL, Huang MT, et al: Inhibition of estradiol-induced mammary proliferation by dibenzoylmethane through the E2-ER-ERE-dependent pathway. Carcinogenesis 27: 131-136, 2006.

41. Lee KW, Kim MS, Kang NJ, et al: H-Ras selectively up-regulates MMP-9 and COX-2 through activation of ERK1/2 and NF-kappaB: an implication for invasive phenotype in rat liver epithelial cells. Int J Cancer 119: 1767-1775, 2006.

42. George J, Banik NL and Ray SK: Knockdown of hTERT and concurrent treatment with interferon-gamma inhibited proliferation and invasion of human glioblastoma cell lines. Int J Biochem Cell Biol 42: 1164-1173, 2010.

43. Park EJ, Lim JH, Nam SI, Park JW and Kwon TK: Rottlerin induces heme oxygenase-1 (HO-1) up-regulation through reactive oxygen species (ROS) dependent and PKC delta-independent pathway in human colon cancer HT29 cells. Biochimie 92: 110-115, 2010.

44. Pan YC, Li CF, Ko CY, et al: CEBPD reverses RB/E2F1-mediated gene repression and participates in HMDB-induced apoptosis of cancer cells. Clin Cancer Res 16: 5770-5780, 2010.

45. Lee KH and Kim JR: Kiss-1 suppresses MMP-9 expression by activating p38 MAP kinase in human stomach cancer. Oncol Res 18: 107-116, 2009.

46. Adamo B, Deal AM, Burrows E, et al: Phosphatidylinositol 3-kinase pathway activation in breast cancer brain metastases. Breast Cancer Res 13: R125, 2011.

47. Cuevas BD, Lu Y, Mao M, et al: Tyrosine phosphorylation of p85 relieves its inhibitory activity on phosphatidylinositol 3-kinase. J Biol Chem 276: 27455-27461, 2001.

48. Liu C, Su T, Li F, et al: PI3K/Akt signaling transduction pathway is involved in rat vascular smooth muscle cell proliferation induced by apelin-13. Acta Biochim Biophys Sin (Shanghai) 42: 396-402, 2010 